\title{
A Mathematical Approach to Optimize Crop Allocation - A Linear Programming Model
}

\author{
Mahak Bhatia*, Anil Rana \\ Bhartiya Skill Development University, Plot 001-002, DTA Mahindra World City, Off, Ajmer Rd, Jaipur, Rajasthan 302037, \\ India
}

Corresponding Author Email: mahak.bhatia@ruj-bsdu.in

https://doi.org/10.18280/ijdne.150215

Received: 20 January 2020

Accepted: 9 March 2020

\section{Keywords:}

crop allocation, crop combination, crop rotation, decision analysis, linear programming, mathematical model, optimization, WSM

\begin{abstract}
Agriculture plays a significant role in the social and economic development of a country. To get optimum farm outputs; decisions such as crop allocation, crop combinations, operational activities performed for crop production are very crucial. All these factors are needed to optimize in each growing season. Proper farm planning and resource allocation play a significant role in optimizing farm revenues. Thus, the study is carried out to analyze the cropping pattern in different districts of Rajasthan. The survey is conducted, to get an insight about the difficulties faced by the growers in each season. It is observed that the farmers in a region often practice crop rotation to enhance the farm output. The Linear programming approach is an effective tool to determine optimal crop combinations and feasibility of decision variables. Thus, a Linear Programming approach is used to determine the solution of the proposed farm model. The results of the mathematical model formulated show an increase in farm output by adopting optimized cropping pattern. The proposed model provides an alternative so as to maximize farm revenues. LINGO 18.0 Software is used to analyze the result of Linear Programming Model. To establish the crop preference WSM is applied to the model.
\end{abstract}

\section{INTRODUCTION}

The availability of resources in a region plays an important role in farm management. Type of crop cultivated, the quantity of crop, crop allocation, crop variety, and crop combinations are the decisions needed to be optimized in the growing season. To analyze the crop allocation \& management alternatives a mathematical model is proposed. Farm planning and management are related to many controllable and uncontrollable factors. To get an insight into these farm parameters Mohamed et al. [1] formulated a crop-mix farm model for a multi-period time horizon. The Linear Programming approach is applied to determine the feasibility of decision variables.

In growing season farmers need to allocate their fields under a different variety of crops depending on previous seasons, crop yield and market price. In addition to this, they have to predict the crop production of the coming season too. Such a decision is quite challenging and critical. However, to support the farmers and to allocate the resource optimally decision support model is formulated by Dury et al. [2]. The model is based on two concepts; crop allocation and crop rotation decision. Crop planning and their allocation are the cornerstone decision of crop management system. Such decisions focus all the complexities involved in a system and alternatives available at the farm level because of their involvement at different stages of crop production.

Thus, crop planning indeed one of the most crucial stages in crop production and has a considerable effect on farm revenues. A crop plan model must provide interaction among all the farm parameters hereby, satisfying all the conflicting objectives. Most of the models that deal with crop plan selections represented through the choice of crop plan or involve crop rotation as a concept.

An integrated farm model is formulated by Nevo et al. [3] with the aim to maximize the farm revenue. It is difficult to achieve the feasible region of such decision variables due to a large number of parameters involved and their complex interrelationships or interactions with each other. In farming system crop plan decisions are quite crucial. Thus, a knowledge-based approach is adopted to formulate an integrated farm system. Such an integrated farm scenario provides an insight to determine the redundancy of the parameters such that it gets altered based on the accessibility and availability of resources in a region.

Along with these parameters, the agriculture sector is affected by varying climatic conditions and scarce availability of water resources too. A study had been carried out by Bullock [4] to determine the effect of adopting crop rotation. It is observed that even a short- rotations such as maizesoybeans will provide a rotational effect and will influence crop productivity. The study concludes that most of the time crop yield is more when cultivated in rotation as compared to that when cultivated as a continuous crop in a season.

Availability of water resources is another major issue of concern especially in arid regions, namely Rajasthan. State being owning a land of 342,239 square kilometers, but still only $52.22 \%$ (179.03 lakh hectares) of land is cultivated as per the reports of RAJRAS [5]. Figure 1 indicates the land distribution in Rajasthan. More than half of the land in Rajasthan is under cultivation indicating that the state is agrarian and supports a diversified variety of crops. Highly cultivated districts in the state includes: Alwar, Jaipur, Bharatpur, Tonk, Churu, Jalore, Jhunjhunu, Sikar, Nagaur, 
Ganganagar and Hanumangarh.

\section{Land Use In Rajasthan in \%}

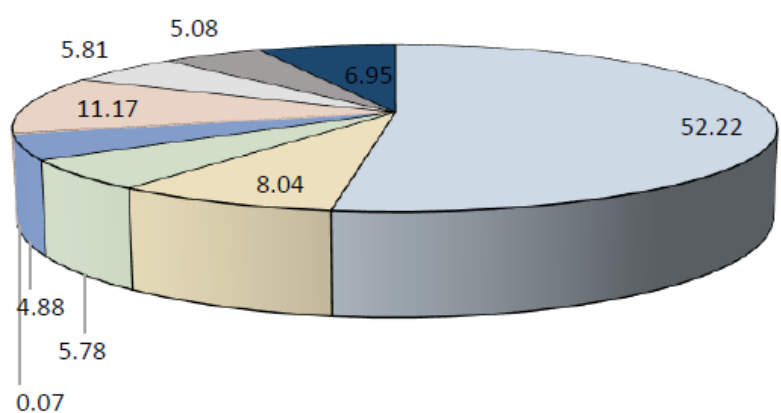

$\square$ Net Sown Area
$\square$ Area Under Forest
$\square$ Non-Agricultural Uses
$\square$ Permanent Pastures and other Grazing Land
I Land Under Miscellaneous Trees and Groves
$\square$ Culturable Wasteland
$\square$ Fallow Land
$\square$ Current Fallow
$\square$ Barren \& Uncultivated Land

Figure 1. Land use pattern in Rajasthan (2019)

However, Jaipur being one of the districts with diversified agriculture, a case study is discussed with the aim to analyze the cropping pattern practiced by the farmers. A model proposed to optimize the farm revenues suggests that some rotations in the cropping pattern will support the framers to increase the revenues. Hence, an emphasis is being laid in allocation of irrigation water resources.

Optimizing an irrigation network and allocating available water resources and arable land are two most important parameters in farm management. The allocation of water resources is quite predictive as it depends on the water requirement of the cultivated crop. Thus, Sabouni \& Mardani [6] proposed a model with the aim to maximize total farm profits by optimally allocating available water resources over a planning horizon. Results show that a Linear Programming approach is an effective tool for channelizing irrigation in fields. Dai \& Li [7] proposed a multistage irrigation water allocation model to resolve the uncertainties involved. Fluctuating availability of water resources and demand, variation in crop yield and economic profits accompanied by the change in the irrigation pattern often challenge the decision-makers in each growing season. These issues become more complex due to an increase in food demand and a reduction in the accessibility of resources. Thus, multistage Stochastic Programming is used to tackle the convexity of decision variables. However, such an approach makes the scenario more practical as it includes the probabilistic approach too.

Such a mathematical model provides support to growers to choose a crop depending on the available resources. Moreover, by determining the solution optimality it becomes easier for the policymakers as well as for the growers to allocate the field in an efficient and effective way.
Rajasthan being an agrarian state supports $80 \%$ of the population. The sector contributes $22.5 \%$ of the state's GDP. About 20 million hectares of land are under cultivation, but, due to inadequate availability of water, only $20 \%$ of total arable land is irrigated. Rajasthan is known for its dry topography and irregular pattern of rainfall. The majority of crops cultivated in Rajasthan are rain-fed. The crops in a region are categorized based on two factors: Crop Water Requirement per hectare and Value of Output derived per hectare. The market demand also influences the decision of crop combinations cultivated by the farmers.

Rajasthan being arid region is majorly affected by the inadequate availability of water resources for irrigating the fields. Most of the crops cultivated in a region are rain-fed. Farmers in Rabi season cultivate the combination of crops that compete with each other in terms of water.

Commonly practiced combinations in a region include: wheat+mustard, wheat+peas, wheat+ mustard+gram. Some regions of the state support maize and sesame as a sole crop in a season. To support the family and to increase the revenue some of the farmers cultivate vegetables too to enhance their revenues. Some of the crops cultivated were: aukra, tomato, onion, chilies, cucumber, brinjal, bitter gourd, bottle gourd, carrot, radish, and fenugreek.

Throughout the growing season, farmers need to allocate their resources to produce the desired quantity of crops. Rajasthan climatic conditions support the growth of two seasonal crops. One is Kharif and another is Rabi. Kharif crops are the crops grown in June and July and harvested in September and October. The crops of this season depend on rains to fulfill their water requirement whereas the crops grown in Rabi season depend mainly on groundwater for irrigation. The cultivated time period for these crops in October and November and harvested in March and April. The crops cultivated in this season include Barley, Wheat, Gram, Pulses and Oil Seeds. Rajasthan is the largest producer of rapeseed \& mustard.

In Rajasthan due to inadequate availability of water resources, farmers left their land fallow in Kharif season. Whereas, some districts with sufficient water prefer to cultivate vegetables during this period.

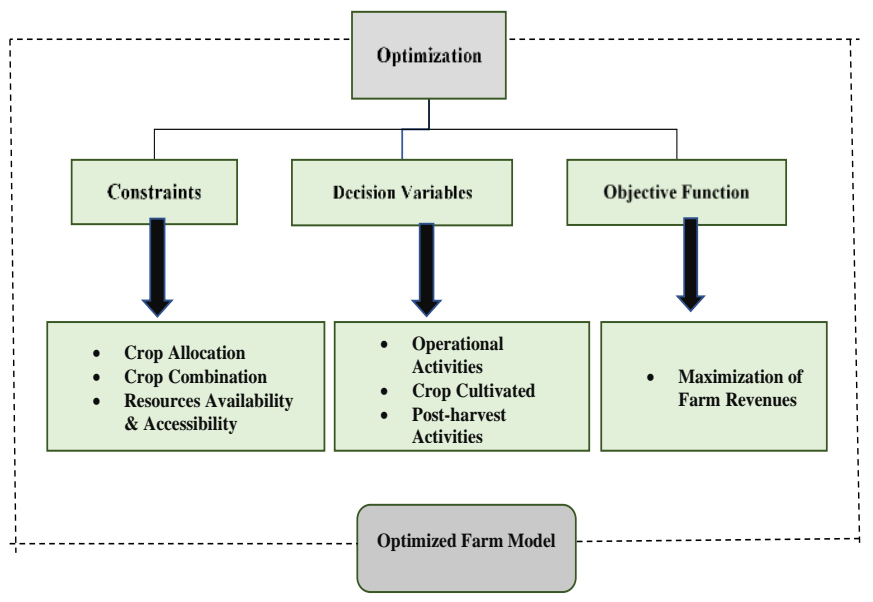

Figure 2. Optimization process

The crop combination allocated for cultivation plays a crucial role in deciding the farm's output. Two farms with different crop combinations were investigated in the Jaipur district of Rajasthan. A comparative analysis is carried out to 
evaluate the optimal crop combinations for the farms of Rajasthan. Thus, a mathematical model is developed by using the Linear Programming approach to enable the decisionmakers to allocate the farm resources optimally. Figure 2 illustrates the optimization process to optimize the farm revenues.

\section{LITERATURE REVIEW}

Due to the complexity of the sector most of the researchers, use a Linear Programming approach to determine the solution feasibility. The simplex algorithm developed by Dantzig, to solve a Linear Programming optimization problem. Linear Programming starts with a primal feasible basis and uses pivot operations to maintain the feasibility of the basis and determine the value of the objective function.

Pap [8] developed a Linear Programming model of an agricultural farm to maximize the total gross margin by adopting crop rotation policy. The results of the study reveal that the farm revenues have shown an increase than that of the traditional crop practices.

With the increase in food demand and technological advancement in the sector, researchers are not only focusing on more crop yield but also sustainable growth. Boyabatlı et al. [9] proposed a dynamic model to allocate farmland under the multiple crops. Since farmers face uncertainties involved in farm revenues thus, a model is developed to consider a crop decision under revenue uncertainty. As per the researchers, knowledge, this is the only literature reviewed so far that considers crop rotation profits along with uncertainty. Farm management under limited water and land resources are one of the crucial aspects of the agriculture sector.

Generally, crop pattern adopted for cultivation is based on the availability of arable land. Thus, growers need to adopt the crop pattern that will maximize the crop yield. Rani \& Rao [10] proposed three approaches based on the availability of water resources. First one formulated a model under adequate availability of water resources, the second model is based on the crop allocation in case of the availability of a limited supply of water. However, in this case, the allocation of the crop is pre-decided. Furthermore, in such a scheme water needs to be optimally distributed among all the cultivated crops to maximize the profits. The last model deals with the allocation of water resources under limited availability of water resources in which crop patterns and combinations can opt freely. It can be concluded that the model deals with both water and land resources simultaneously. Thus, a multiobjective Linear Programming model is proposed to maximize the revenues and minimize the input cost. The result of the model indicates that the optimization technique will significantly improve the farmer's profit by optimally allocating land and water resources.

Traditionally, irrigation is based on cropping scenarios to maximize farm revenues by optimizing the pattern of irrigation. Thus, some of the researchers felt that the multicriterion approach is the best tool to optimize farm resources. This is because of the multi-objective programming deals with more than one objective simultaneously, hence providing a trade-off among the solutions obtained. A model is formulated by Tsakiris \& Spiliotis [11] to optimize farm revenues by optimizing the irrigation pattern using a multi-objective approach. To optimize the available resources the basis for classification is kept the same throughout the formulation.
Moreover, the net farm benefit was included as one of the model constraints rather than making it a part of the objective function. Well, the defined methodology is followed to construct a model. With the increase in production to feed the growing population the need for proper management of warehouses and inventories has been evolved.

Sarker \& Quaddus [12] develop a mathematical model to evaluate the feasibility of a region by using a multi-objective approach. The paper provides an insight into how a multiobjective approach can be used for optimizing farm resources. Crop planning is, generally, evaluated as a single-objective problem to maximize the farm revenues and minimize cultivation cost by listing constraints.

To examine the benefit of sensory technologies numerical analysis is conducted by Li \& Wang [13] under different farm operational activities. The research findings reveal that datadriven by sensor networks predict the remaining shelf-life of the product. Some other important parameters of the Agrisupply chain are food quality, food safety, and sustainability. Hence, the management of food distribution is focused on the researchers both in practice and literature. Small farmers often face a problem of resource allocation due to the inappropriate availability of capital. Thus, Majeke et al. [14] proposed a model to maximize farm profit for a set of constraints that limits the model. Farmers in a region often use trial and error methods to improve crop productivity. Thus, a comparative analysis of traditional and optimized cropping pattern is carried out. The results of the study provide an alternative for growers to increase farm revenues.

Visagie \& Ghebretsadik [15] proposed a mathematical model to study the impact of having an alternate crop rotation to decision planning and integrated crop-livestock scenario. The farm activity is compacted with different crops and livestock management. The constraints faced by the farmers include crop allocation, size of livestock, the quantity of yield to sell in market mechanized cost and other operational farm activities. The result indicates that in determining an optimal plan, an integrated crop-livestock scenario plays a significant role. Crop rotation pattern is sensitive to risk and involvement of such parameter in formulation affects land allocation and production level of husbandry. However, it is concluded that crop rotation is one of the crucial parameters that if panned precisely will increase the farm revenues.

Since farm management is important from both economic and social points of view, thus there is a need to optimize the farm resources efficiently. With population growth, there is a demand for more crop production. One way to increase the crop yield is to increase the area under cultivation and another is to increase the crop productivity per hectare. As a result, of efficiently allocating the resources to increase crop yield Sofi et al. [16] used a Linear Programming approach for allocating a combination of five crops.

Due to the growing demand for water for both sufficient and satisfied quantity, the need for water allocation in farms has emerged. The majority of available water is used by the agriculture sector for irrigation. Thus, to improve the benefit and for the sustainability of resources, it is important to allocate the water resources sustainably. A multi-objective water allocation model is proposed by Li \& Guo [17]. To validate the model, it is applied to Minqin's irrigation areas, Gansu Province, China. The objective of the model is to optimize the economic, social and ecological benefits of a region. Thus, different water types (groundwater and surface water) were considered for irrigating the fields. The result 
indicates that the model provides a sustainable approach to allocate water resources in water-deficient regions and thus provides an alternative to allocate the resource.

Thus, a mathematical model crop cultivated in different districts of Rajasthan were studied. From the literature reviewed, it is analysed that none of the studies is being conducted that will analyse the cropping pattern and crop combination underwater inadequate conditions simultaneously to maximize the farm output and minimize the input cost.

\section{STUDY REGION}

Rajasthan is the northwestern state of India that occupies 34.2 million hectares of land and $10.4 \%$ of India's total area. Around $70 \%$ of the state's population is engaged in agricultural and allied sectors. Though the state has $83 \%$ of total water resources, only $36.3 \%$ or 6.66 million hectares of net sown area are irrigated. Out of the total irrigated region, $73 \%$ of the farms depend on groundwater to fulfill the irrigation requirements while the remaining farms dependent on canals.

\subsection{Existing cropping pattern}

In Jaipur, crops like maize, bajra, wheat, mustard, etc. are grown. The farmers in a district grow crops in combinations with another crop. The existing crop combinations in a district are determined by interviewing the farmers in Rabi season: wheat + mustard, wheat + peas, wheat + mustard + black gram, wheat + mustard + fodder.

Area Under Different Crops

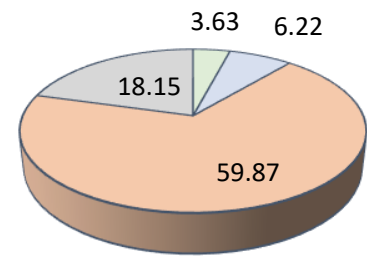

口Cereals 口Pulses [Food grains DOilseeds

Figure 3. Area under different crops in Jaipur (in \%) Source: Commissionerate of Agriculture, Rajasthan -Jaipur

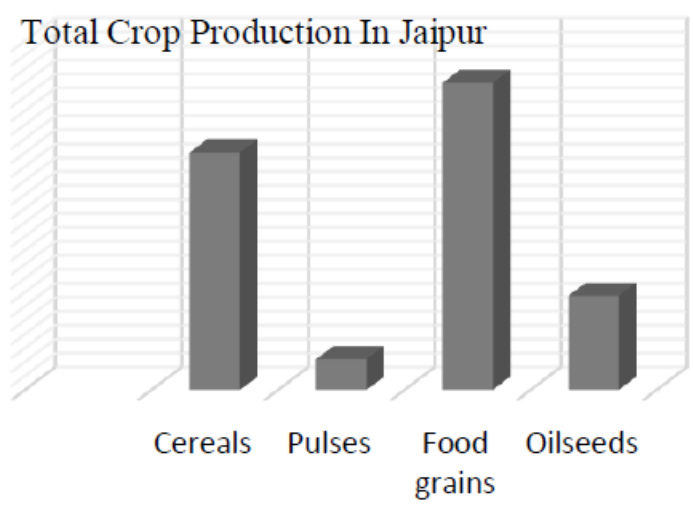

Figure 4. Total production of crops in Jaipur (in tonnes) (Source: Commissionerate of Agriculture, Rajasthan -Jaipur)
It is observed that small farmers often support their farm scenario with the livestock. Though livestock did not contribute optimally in farm revenues to some extent it will reduce their input cost. Figure 3 and Figure 4 illustrates the percentage of area and the production under different food crops in Jaipur.

\section{METHODOLOGY}

The Linear Programming approach is used to find the feasibility region of the developed farm model. Data is collected by interviewing a farmer. The aim of the study is to determine the cropping pattern, crop combinations and inputs carried out by the farmers to determine the feasible optimal solution of the model developed. LINGO 18.0 is used to analyse the results. LINGO is a tool that is designed to solve Linear, Non-Linear, Quadratic, Integer Models fast and provides an accurate result. Solution window of LINGO provides with the following information:

- For an optimal solution reduced cost is always zero.

- For the variables that do not contribute to providing an optimal result, reduced costs indicate how the value of cost vector would change if one unit of the cost associated with the decision variable is included in the solution.

- If all the resources were utilized efficiently then surplus/slack variable associated with it will be zero otherwise, non-zero.

- A positive value of the slack/surplus variable indicates how many more units of cost vector are needed to add to get an optimal result.

- A negative value of the slack/surplus variable indicates that the constraint is redundant and can be removed.

Thus, LINGO Software determines the variations needed to be altered in cost and activity vector to get an optimal solution.

The Simplex Algorithm approach invented by George Dantzig in 1947 is used to solve linear programming. It is an iterative process that improves the solution at each stage by adding the basic variable at each stage and removing the nonbasic variable.

A Random Sampling technique is adopted to choose the district with diversity in crop adopted for cultivation. On the basis of labour cost and production WSM (Weighted Sum Model) technique is adopted so as to rank the crop based on the aforementioned parameters. An integrated approach of Linear Programming and WSM (Weighted Sum Model) helps us to get an insight about the cropping scenario in district.

Linear Programming approach will determine all the parameters and suggests an alternative to be adopted to optimized the farm revenue i.e. based on the parameters what can be the alternate crop that can be cultivated along with the existing crops. However, WSM model will determine the crop preferences depending on the input cost and the output in terms of production.

\section{MODEL FORMULATION}

Farm 1: The farmer is owning 8.02 ha (50 bighas) of land that is used for livestock, peas, and wheat production. The 
farmer uses wheat straw as a fodder to feed the livestock. The problem is to arrive at an optimal decision involving crop combinations, allocation of farm resources, the variety of crops to grow, how much to produce and what are the procedures adopted to produce as to reduce the input cost. A farmer by experience had planned his land to allocate 4.81 ha (30 bighas) for peas, 1.92 ha (12 bighas) for wheat and he has 3 buffaloes and 1 cow. His resources include labor and land. Table 1 indicates the farm practice operated by grower and Table 2 illustrates the optimized cropping pattern.

Farm 2: The farmer is owning 10.43 ha (65 bighas) of land that is used for pigs, mustard, grams, and wheat production.
The problem was to determine an optimal no. of pigs and allocation of crops that how the farm production can be increased either by introducing a new crop in the farm or by increasing the size of livestock. Farmer allocates 4.81 ha (30 bighas) for mustard, 1.6 ha (10 bighas) for wheat 1.6 ha (10 bighas) for a gram and he has 250-300 pigs. Table 3 indicates the farm practice operated by grower and Table 4 illustrates the optimized cropping pattern.

\section{Farm 1}

$\mathrm{X}_{1}=\mathrm{kg}$ of peas produced per hectare

$\mathrm{x}_{2}=\mathrm{kg}$ of wheat produced per hectare

Table 1. Existing farm model

\begin{tabular}{ccccc}
\hline Objective & \multicolumn{4}{c}{ Max. $\mathrm{Z}=6500 \mathrm{x}_{1}+3238 \mathrm{x}_{2}$} \\
\hline & Activity Coefficients & Sign Constraint & Requirement Vector & Constraints \\
\hline Constraints & $4.81 \mathrm{x}_{1}+1.92 \mathrm{x}_{2}$ & $\leq$ & 8.02 & Land \\
& $250 \mathrm{x}_{1}+200 \mathrm{x}_{2}$ & $\leq$ & 500 & Labor \\
& $1000 \mathrm{x}_{1}+1500 \mathrm{x}_{2}$ & $\leq$ & 2500 & Water \\
& $\mathrm{x}_{1}+\mathrm{x}_{2}$ & $\leq$ & 100000 & cost of seeds and fertilizers \\
\hline Non-Negativity Constraints & & & $\mathrm{x}_{1}, \mathrm{x}_{2} \geq 0$ & \\
\hline
\end{tabular}

$\mathrm{X}_{1}=\mathrm{kg}$ of peas produced per hectare

$\mathrm{x}_{2}=\mathrm{kg}$ of wheat produced per hectare $\mathrm{x}_{3}=\mathrm{kg}$ of mustard produced per hectare (Note: these variables have to come above Table 2)

Table 2. Optimized farm model (Farm 1)

\begin{tabular}{ccccc}
\hline Objective & \multicolumn{4}{c}{ MAX. Z $=6500 \mathrm{x}_{1}+5875 \mathrm{x}_{2}+4285 \mathrm{x}_{3}$} \\
\hline \\
\cline { 2 - 5 } Constraints & Activity Coefficients & Sign Constraint & Requirement Vector & Constraints \\
& $4.81 \mathrm{x}_{1}+1.8 \mathrm{x}_{2}+2 \mathrm{x}_{3}$ & $\leq$ & 8.02 & Land \\
& $250 \mathrm{x}_{1}+150 \mathrm{x}_{2}+150 \mathrm{x}_{3}$ & $\leq$ & 800 & Labor \\
& $1000 \mathrm{x}_{1}+1500 \mathrm{x}_{2}+900 \mathrm{x}_{3}$ & $\leq$ & 3200 & Water \\
& $\mathrm{x}_{1}+\mathrm{x}_{2}+\mathrm{x}_{3}$ & $\leq$ & 110000 & cost of seeds and fertilizers \\
\hline Non-Negativity Constraints & & & $\mathrm{x}_{1}, \mathrm{x}_{2}, \mathrm{x}_{3} \geq 0$ & \\
\hline
\end{tabular}

Farm 2

$\mathrm{x}_{1}=\mathrm{kg}$ of mustard produced per hectare

$\mathrm{x}_{2}=\mathrm{kg}$ of wheat produced per hectare
$\mathrm{X}_{3}=\mathrm{kg}$ of gram produced per hectare

$\mathrm{x}_{4}=$ size of livestock (note: these has to come above Table 3)

Table 3. Existing farm model

\begin{tabular}{ccccc}
\hline Objective & & MAX. Z $=7000 \mathrm{x}_{1}+3000 \mathrm{x}_{2}+2500 \mathrm{x}_{3}+300 \mathrm{x}_{4}$ & \\
\hline & Activity Coefficients & Sign Constraint & Requirement Vector & Constraints \\
\hline & $4.81 \mathrm{x}_{1}+1.6 \mathrm{x}_{2}+1.6 \mathrm{x}_{3}+1.0 \mathrm{x}_{4}$ & $\leq$ & 10.43 & land \\
Constraints & $200 \mathrm{x}_{1}+200 \mathrm{x}_{2}+150 \mathrm{x}_{3}+300 \mathrm{x}_{4}$ & $\leq$ & 3000 & labor \\
& $1000 \mathrm{x}_{1}+1500 \mathrm{x}_{2}+500 \mathrm{x}_{3}+800 \mathrm{x}_{4}$ & $\leq$ & 4000 & water \\
& $\mathrm{x}_{1}+\mathrm{x}_{2}+\mathrm{x}_{3}$ & $\leq$ & 90000 & cost of seeds and fertilizers \\
& $\mathrm{x}_{4}$ & $\leq$ & 3000 & cost of feeding livestock \\
\hline Non-Negativity & & & \multirow{2}{*}{$\mathrm{x}_{1}, \mathrm{x}_{2}, \mathrm{x}_{3}, \mathrm{x}_{4} \geq 0$} \\
Constraints & & &
\end{tabular}

$\mathrm{X}_{1}=\mathrm{kg}$ of peas produced per hectare

$\mathrm{x}_{2}=\mathrm{kg}$ of wheat produced per hectare
$\mathrm{X}_{3}=\mathrm{kg}$ of mustard produced per hectare (note: these has to come above Table 4)

Table 4. Optimized farm model (Farm 2)

\begin{tabular}{ccccc}
\hline Objective & \multicolumn{5}{c}{ Max Z $=9075 \mathrm{x}_{1}+4670 \mathrm{x}_{2}+3900 \mathrm{x}_{3}$} & Constraints \\
\hline & Activity Coefficients & Sign Constraint & Requirement Vector & land \\
\cline { 2 - 5 } Constraints & $5 \mathrm{x}_{1}+2.0 \mathrm{x}_{2}+1.8 \mathrm{x}_{3}$ & $\leq$ & 10.43 & labour \\
& $200 \mathrm{x}_{1}+200 \mathrm{x}_{2}+150 \mathrm{x}_{3}$ & $\leq$ & 260 & water \\
& $1000 \mathrm{x}_{1}+900 \mathrm{x}_{2}+250 \mathrm{x}_{3}$ & $\leq$ & $\leq 0000$ & cost of seeds and fertilizers \\
\hline Non-Negativity Constraints & $\mathrm{x}_{1}+\mathrm{x}_{2}+\mathrm{x}_{3}$ & $\leq$ & $\mathrm{x}_{1}, \mathrm{x}_{2}, \mathrm{x}_{3} \geq 0$ & \\
\hline
\end{tabular}




\section{RESULTS}

The results of the study reveal that the farm returns increased to $68 \%$ (farm 1) and $16.5 \%$ (farm 2). Linear programming approach as a tool provides with the numeric solution that to what extent the variations in the area under each type of crop and other parameters will be carried out in order to increase farm revenues. The reduced value associated with each cost vector in objective function provides the variations that can be performed to get an upper and lower bound of the cost coefficients such that the optimal value can be improved. However, the simplex algorithm adopted to solve Linear Programming problem is an iterative process that will improve the optimal value of the decision variable at each iteration. Table 5 and Table 6 represents the optimal value of the existing and optimized value of farm 1. Table 7 and Table 8 represents the optimal value of the existing and optimized value of farm 2 .

\section{$\underline{\text { Optimized Model (Farm 1) }}$}

Table 5. Optimal values for the existing cropping pattern (Farm 1)

\begin{tabular}{ccc}
\hline Variable & Value & Reduced Cost \\
\hline $\mathbf{x}_{1}$ & 1.365439 & 0.000000 \\
$\mathbf{x}_{\mathbf{2}}$ & 0.7563739 & 0.000000 \\
\hline
\end{tabular}

Due to the iterative nature of algorithm, the redundant constraints are identified. Moreover, all the decision variables lie in the convex hull of the decision variable thus, making a $\underline{\text { Farm1 }}$
Linear Programming an efficient tool in determining the optimality of decision variables.

However, the summarised existing and optimized value of decision variables for farm 1 and farm 2 is illustrated in Table 9 and Table 10 respectively.

Table 6. Optimized cropping pattern value (Farm 1)

\begin{tabular}{ccc}
\hline Variable & Value & Reduced Cost \\
\hline $\mathbf{x}_{1}$ & 0.3512237 & 0.000000 \\
$\mathbf{x}_{\mathbf{2}}$ & 0.000000 & 236.3246 \\
$\mathbf{x}_{3}$ & 3.165307 & 0.000000 \\
\hline
\end{tabular}

\section{$\underline{\text { Optimized Model (Farm 2) }}$}

Table 7. Optimal values of existing cropping pattern (farm 2)

\begin{tabular}{ccc}
\hline Variable & Value & Reduced Cost \\
\hline $\mathbf{x}_{1}$ & 0.000000 & 264.0625 \\
$\mathbf{x}_{2}$ & 0.7406250 & 0.000000 \\
$\mathbf{x}_{3}$ & 5.778125 & 0.000000 \\
$\mathbf{x}_{4}$ & 0.000000 & 1506.250 \\
\hline
\end{tabular}

Table 8. Optimized cropping pattern (farm 2)

\begin{tabular}{ccc}
\hline Variable & Value & Reduced Cost \\
\hline $\mathbf{x}_{1}$ & 0.5729885 & 0.000000 \\
$\mathbf{x}_{2}$ & 1.649425 & 0.000000 \\
$\mathbf{x}_{3}$ & 2.370115 & 0.000000 \\
\hline
\end{tabular}

Table 9. Optimal solution of the existing \& optimized cropping pattern

\begin{tabular}{ccc|ccc}
\hline \multicolumn{3}{c|}{ Existing Cropping Pattern } & \multicolumn{3}{c}{ Optimized Cropping Pattern } \\
\hline Crops & Decision Variables & Optimal values & Crops & Decision Variables & Optimal values \\
\hline Peas & $\mathrm{X}_{1}$ & 1.365439 & Peas & $\mathrm{X}_{1}$ & 0.351223 \\
Wheat & $\mathrm{x}_{2}$ & 0.7563739 & Wheat & $\mathrm{x}_{2}$ & 0.000000 \\
- & - & & Mustard & $\mathrm{X}_{3}$ & 3.165307 \\
\multicolumn{2}{c|}{ Optimal Returns (Rs) } & $3,11,324$ & \multicolumn{2}{c}{ Optimal returns (Rs) } & $6,38,148$ \\
\hline
\end{tabular}

\section{Farm 2}

Table 10. Optimal solution of the existing \& optimized cropping pattern

\begin{tabular}{ccc|ccc}
\hline & \multicolumn{2}{c}{ Existing Cropping Pattern } & \multicolumn{3}{c}{ Optimized Cropping Pattern } \\
\hline Crops & Decision Variables & Optimal values & Crops & Decision Variables & Optimal values \\
\hline Mustard & $\mathrm{X}_{1}$ & 0.000000 & Mustard & $\mathrm{X}_{1}$ & 0.5729885 \\
Wheat & $\mathrm{X}_{2}$ & 0.7406250 & Wheat & $\mathrm{X}_{2}$ & 1.649425 \\
Gram & $\mathrm{X}_{3}$ & 5.778125 & Gram & $\mathrm{X}_{3}$ & 2.370115 \\
Pigs & $\mathrm{X} 4$ & 0.000000 & - & - & - \\
\multicolumn{2}{c}{ Optimal Returns (Rs.) } & $6,67,414$ & Optimal Returns (Rs.) & $7,87,172$ \\
\hline
\end{tabular}

Table 11. Optimal solution of the existing \& optimized cropping pattern

\begin{tabular}{ccc|ccc}
\hline \multicolumn{2}{c|}{ Farm 1 } & \multicolumn{3}{c}{ Farm 2 } \\
\hline Decisi-on Variab-les & Existing Results & Optimize Results & Decisio-n Variables & Existin-g Results & Optimiz-e Results \\
\hline $\mathbf{X}_{\mathbf{1}}{ }^{*}$ & 1.365 & 0.351 & $\mathbf{X}_{\mathbf{1}}{ }^{*}$ & 0.000 & 0.572 \\
$\mathbf{X}_{\mathbf{2}}{ }^{*}$ & 0.756 & 0.000 & $\mathbf{X}_{\mathbf{2}}{ }^{*}$ & 0.740 & 1.649 \\
$\mathbf{X}_{\mathbf{3}}{ }^{*}$ & - & 3.165 & $\mathbf{X}_{\mathbf{3}}{ }^{*}$ & 5.778 & 2.370 \\
$\mathbf{X}_{\mathbf{4}}{ }^{*}$ & - & - & $\mathbf{X}_{\mathbf{4}}{ }^{*}$ & 0.000 & - \\
Farm returns (Rs) & $3,11,324$ & $6,38,148$ & Farm returns (Rs) & $6,67,414$ & $7,87,172$ \\
\hline
\end{tabular}




\section{DISCUSSION AND CONCLUSION}

- Introduction of mustard as a new crop increases the farm 1 productivity

- Increasing the area under crop production and eliminating piggery farm from farm 2 enhances the farm output.

- The operational cost will reduce if the crops of the same family are cultivated.

- Keeping livestock supports cultivation activities.

Livestock also reduces the cost of cultivation as it provides natural fertilizers and improves soil fertility.

Optimal farm returns obtain (Table 11) by using Linear Programming approach provide an insight about the available alternatives that will be performed to enhance the farm profit. Further, the results show that an integrated farm system will not only increase the farm gross returns but also reduces the operational cost. Adoption of crop rotation will also improve the crop productivity and improves the soil quality.

Negative trendline of the (Figure 5) graph for optimized value indicates that the particular decision variable did not contribute in optimized value of the objective function. There is no such trendline (Figure 6) in case of farm 2. However, the shadow price associated with the activity coefficient of the vector will reduce the optimized value by increasing the value of the activity coefficient respectively.

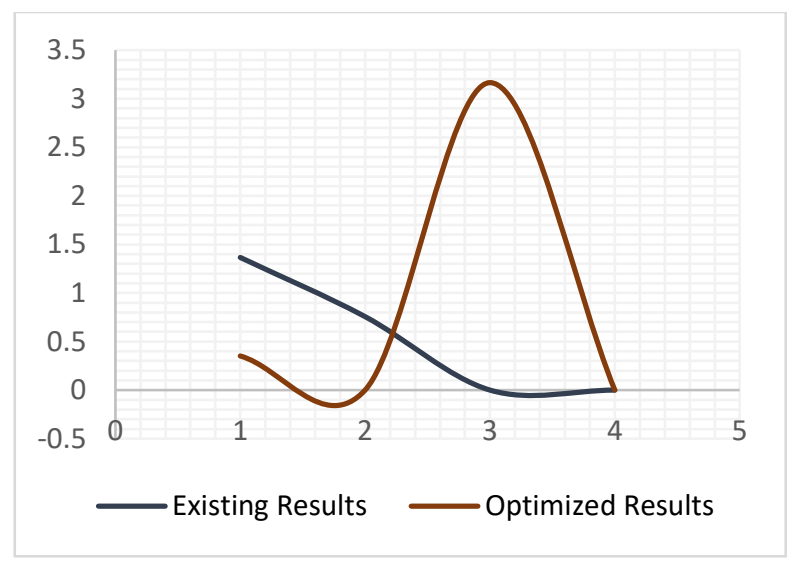

Figure 5. The existing and optimize farm return of Farm 1

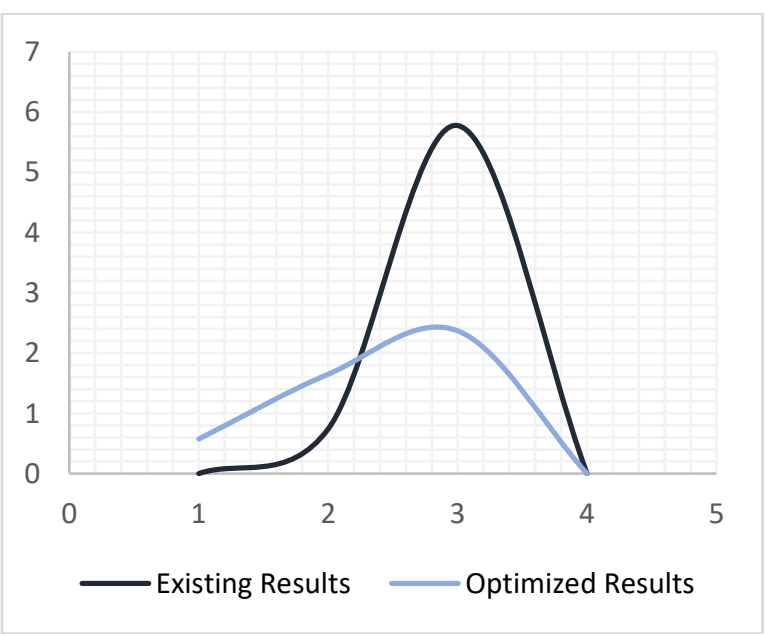

Figure 6. The existing and optimize farm return of Farm 2

Linear Programming Model illustrates that in case of Farm
1 the existing cropping pattern provides preference to crop 1 as compared to crop 2 whereas in case of farm 2 a preference is given to crop 2 and 3 as compared to that of 1 and 4 . However, when optimized cropping pattern is practiced by growers a preference is given to crop 1 and crop 3 (introduced crop) rather than crop 2 for farm 1 whereas in case of farm 2 preferences were for crop 1, 2 and 3.

The results of the methodologies adopted is shown in Table 12 and can be depicted by Figure 7 indicates that in case of farm 1 though $\mathrm{x}_{3}$ variable attributed more feasible value but WSM approach give more preference to $\mathrm{x}_{1}$ variable.

Table 12. Comparison analysis of the methodologies

\begin{tabular}{cccc}
\hline & Linear Model & & WSM \\
\hline & Optimized & Decision & Preferences \\
Values & Variables & \\
\hline Farm 1 & 0.3512237 & Peas & 1 \\
& 3.165307 & Mustard & 2 \\
\hline Farm 2 & 0.5729885 & Mustard & 3 \\
& 1.649425 & Wheat & 1 \\
& 2.370115 & Gram & 2 \\
\hline
\end{tabular}

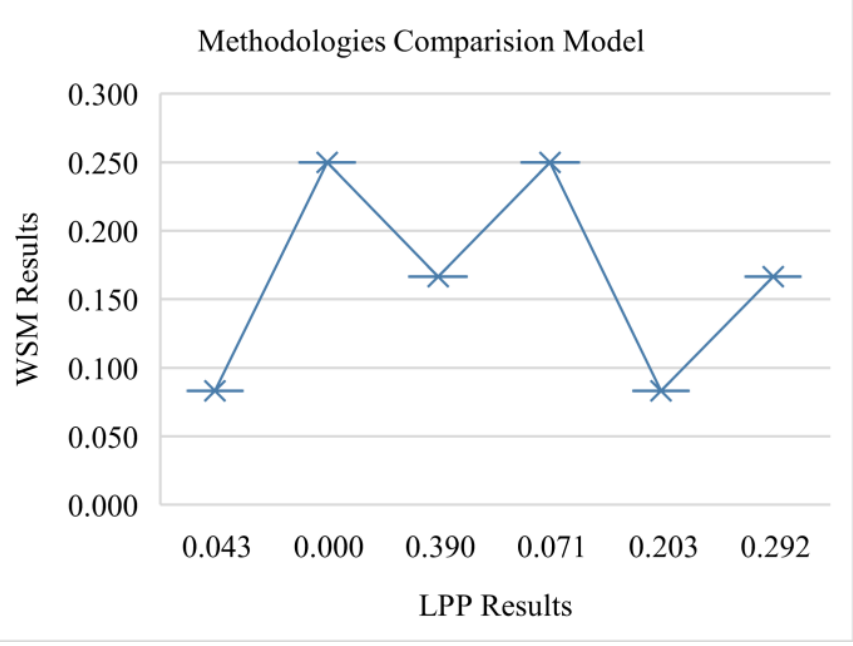

Figure 7. Comparison of WSM and LPP results

\section{REFERENCES}

[1] Mohamed, H.I., Mahmoud, M.A., Elramlawi, H.R.K., Ahmed, S.B. (2016). Development of mathematical model for optimal planning area allocation of multi crop farm. International Journal of Science and Engineering Investigations, 5(59): 7.

[2] Dury, J., Schaller, N., Garcia, F., Reynaud, A., Bergez, J.E. (2012). Models to support cropping plan and crop rotation decisions. A review. Agronomy for Sustainable Development, 32(2): 567-580. https://doi.org/10.1007/s13593-011-0037-x

[3] Nevo, A., Oad, R., Podmore, T.H. (1994). An integrated expert system for optimal crop planning. Agricultural Systems, 45(1): 73-92. https://doi.org/10.1016/S0308521X(94)90281-X

[4] Bullock, D.G. (1992). Crop rotation. Critical Reviews in Plant Sciences, 11(4): 309-326. https://doi.org/10.1080/07352689209382349

[5] RAJRAS. (2019). Land use pattern of Rajasthan. RajRAS - Rajasthan RAS. 
https://www.rajras.in/index.php/land-use-patternrajasthan/, accessed on Jan. 21, 2020.

[6] Sabouni, M.S., Mardani, M. (2013). Application of robust optimization approach for agricultural water resource management under uncertainty. Journal of Irrigation and Drainage Engineering, 139(7): 571-581. https://doi.org/10.1061/(ASCE)IR.1943-4774.0000578

[7] Dai, Z.Y., Li, Y.P. (2013). A multistage irrigation water allocation model for agricultural land-use planning under uncertainty. Agricultural Water Management, 129: 69-79. https://doi.org/10.1016/j.agwat.2013.07.013

[8] Pap, Z. (2008). Crop rotation constraints in agricultural production planning. 2008 6th International Symposium on Intelligent Systems and Informatics, pp. 1-5. https://doi.org/10.1109/SISY.2008.4664951

[9] Boyabatl1, O., Nasiry, J., Zhou, Y. (2019). Crop planning in sustainable agriculture: dynamic farmland allocation in the presence of crop rotation benefits. Management Science, 65(5):

1949-2443. https://doi.org/10.1287/mnsc.2018.3044

[10] Rani, Y.R., Rao, D.P.T. (2012). Multi objective crop planning for optimal benefits. International Journal of Engineering Research, 2(5): 10.

[11] Tsakiris, G., Spiliotis, M. (2006). Cropping pattern planning under water supply from multiple sources. Irrigation and Drainage Systems, 20(1): 57-68. https://doi.org/10.1007/s10795-006-5426-y
[12] Sarker, R.A., Quaddus, M.A. (2002). Modelling a nationwide crop planning problem using a multiple criteria decision making tool. Computers \& Industrial Engineering, $\quad 42(2-4)$ : 541-553. https://doi.org/10.1016/S0360-8352(02)00022-0

[13] Li, D., Wang, X. (2017). Dynamic supply chain decisions based on networked sensor data: An application in the chilled food retail chain. International Journal of Production Research, 55(17): 5127-5141. https://doi.org/10.1080/00207543.2015.1047976

[14] Majeke, F., Majeke, J., Chabuka, N.T., Mufandaedza, J., Shoko, M.D., Chirima, J., Makoni, T., Matete, C. (2013). A farm resource allocation problem: A case study of model A2 resettled farmers in Bindura, Zimbabwe. International Journal of Economics and Management Sciences, 2(07): 4.

[15] Visagie, S.E., Ghebretsadik, A.H. (2005). Modelling risk in farm planning. Agrekon, 44(4): 561-585. https://doi.org/10.1080/03031853.2005.9523728

[16] Sofi, N.A., Ahmed, A., Ahmad, M., Bhat, B.A. (2015). Decision making in agriculture: A linear programming approach. Economics, 13(2): 160-169.

[17] Li, M., Guo, P. (2014). A multi-objective optimal allocation model for irrigation water resources under multiple uncertainties. Applied Mathematical Modelling, 38(19-20): https://doi.org/10.1016/j.apm.2014.03.043 